\title{
Osteoarticular diseases and physical performance of Brazilians over 80 years old
}

\author{
Doenças osteoarticulares e desempenho físico \\ de idosos brasileiros com idade igual ou superior a 80 anos
}

\author{
Vanessa Ribeiro dos Santos ${ }^{1}$ \\ Luís Alberto Gobbo ${ }^{2}$ \\ Diego Giulliano Destro Christofaro ${ }^{2}$ \\ Igor Conterato Gomes ${ }^{3}$ \\ Jorge Mota ${ }^{4}$ \\ Sebastião Gobbi ${ }^{1}$ \\ Ismael Forte Freitas Júnior ${ }^{2}$
}

${ }^{1}$ Programa de Pós-

Graduação em Ciências da Motricidade, Universidade Estadual Paulista (UNESP). Av. 24-A/1515, Jardim Bela Vista. 13506-900 Rio Claro SP Brasil. van_vrs@yahoo.com.br ${ }^{2}$ Departamento de Educação Física, Faculdade de Ciências e Tecnologia, Universidade Estadual Paulista Julio de Mesquita Filho. Presidente Prudente SP Brasil.

${ }^{3}$ Programa de PósGraduação em Saúde Pública, Faculdade de Saúde Pública, Universidade de São Paulo. São Paulo SP Brasil.

${ }^{4}$ Faculdade de Desporto, Universidade do Porto.

Porto Portugal.
Abstract Objective: To investigate the physical performance of Brazilian individuals older than 80 years with and without OD. Methods: The sample consisted of 135 individuals (aged > 80 years) of both gender. Identification of osteopenia/osteoporosis was verified by Dual Energy $X$-ray Absorptiometry, and the presence of others osteoarticular diseases (OD) was obtained using a questionnaire of morbidities. Physical performance was analyzed by motor tests. Results: Men presented higher proportion of osteopenia/osteoporosis compared to women $(p=0.013)$. The proportion of older people with arthritis/osteoarthritis for women and men was 33\% and 26\%, respectively, and with $O D$ in the spine was 19\% and $12 \%$, respectively. No significant difference for physical performance, measured by each test and overall score, was observed between groups of OD. According to gender, male with OD presented lower performance in gait speed, balance and overall score $(p<0.05)$, while older people with osteopenia/osteoporosis are at higher risk for low physical performance (OR 2.73; CI 95\% 1.315.66). Conclusion: In conclusion it was verified in older people with age of 80 years or more, a high prevalence of $O D$, especially in men, and the presence of these diseases interfered negatively their physical performance.

Key-words Osteoporosis, Arthritis, Osteoarthritis, Physical performance, Elderly
Resumo Objetivo: Investigar o desempenho físico de idosos brasileiros com idade superior a 80 anos com e sem doenças osteoarticulares (DO). Métodos: Foram avaliados 135 indivíduos (idade $>80$ anos) de ambos os sexos. A presença de osteoporose foi analisada por meio da técnica de Absorptiometria de Raios-X de Dupla Energia, e a prevalência de outras doenças osteoarticulares foi verificada por meio de um questionário resumido de morbidades referidas. O desempenho físico foi avaliado por testes motores. Resultados: Os homens apresentaram maior proporção de osteopenial osteoporose comparados às mulheres $(p=0,013)$. A proporção de idosos com artrite/artrose foi $33 \%$ e $26 \%$, e com alguma doença na coluna foi $19 \%$ e $12 \%$, para homens e mulheres, respectivamente. Não houve diferença significativa no desempenho físico para a amostra geral. Segundo o sexo, homens com DO apresentaram menor desempenho nos testes de caminhada, equilíbrio e escore total ( $p$ $<0,05$ ). Idosos com osteopenia/osteoporose apresentaram maior risco para limitação física (OR 2,73; IC 95\% 1,31-5,66). Conclusão: Foi verificado em idosos com idade igual ou superior a 80 anos alta prevalência de doenças osteoarticulares, especialmente em homens, e sua presença interfere negativamente no desempenho físico.

Palavras-chave Osteoporose, Artrite, Artrose, Desempenho físico, Idosos 


\section{Introduction}

The increasing number of the older people population in Brazil occurs considerably faster, with higher increases in group aged over 80 years ${ }^{1}$. In this population, it is observed an increase in the prevalence of diseases related to the osteoarticular system ${ }^{2}$, such as osteoarticular diseases (OD). The OD are among the most prevalent diseases in the older people subjects around the world ${ }^{3,4}$ and in Brazi ${ }^{5,6}$, and are responsible for decreased physical performance and increased number of falls and fractures in older people ${ }^{7-9}$, contributing to the loss of autonomy, greater dependency on the performance of activities of daily living, increases the demand for public health services ${ }^{10-11}$ and mortality.

Older people with different OD may differ on commitment of the physical performance. Thus, the assessment of the physical performance in older people with OD, especially those older than 80 years old, that have high prevalence this diseases, is important for falls and fractures prevention as well as for the maintenance of health.

Thus, the assessment of physical performance in older people with OD, especially those older 80 years old who have high prevalence of this disease, is very important for public health purposes, in view of the possibility of cost reduction with hospitalizations and treatments of bone fractures due to falls.

However, a limited number of studies investigated the relationship between the presence of $\mathrm{OD}$ and reduced physical performance in Brazilian individuals older than 80 years. Thus, the aim of this study was to investigate the physical performance of Brazilian individuals older than 80 years with and without osteoarticular diseases.

\section{Materials e Methods}

\section{Sample}

This cross-sectional study was conducted in the city of Presidente Prudente $(\sim 210,000$ in habitants), the largest city of the western region of the state of São Paulo, Brazil, with a Human Development Index of $0.846^{12}$.

The data collection was carried out between October 2009 and May 2010. Subjects aged 80 years or over of both genders were invited to participate in the study. The city health department released the name, address and telephone number of individuals aged 80 or older who used the public health services in the city. The individuals were contacted by phone and an invitation was also published in local media.

As exclusion criteria, individuals who did not walk, living in the rural areas, institutionalized, with pacemaker and individuals with incomplete data in our database were withdrawn from the sample. Thus, the sample consisted of 135 individuals of both gender: 86 women $(83.3 \pm 3$ years) and 49 men $(83.5 \pm 2.8$ years $)$.

Participants of this study were informed about the objectives and the methodology used for data collection. Only those who signed the "Instrument of Consent" were part of the sample. All protocols were reviewed and approved by the Research Ethics Committee of the Universidade Estadual Paulista.

\section{Anthropometric measurements}

For evaluation of body weight a digital scale was used, Filizola ${ }^{\circledR}$ brand, accuracy of $0.1 \mathrm{~kg}$ and maximum capacity of $150 \mathrm{~kg}$. Height was measured with metal stadiometer fixed, accuracy of $0.1 \mathrm{~cm}$ and maximum length of two meters. All anthropometric measurements were performed following the procedures described by Freitas Júnior. et al. ${ }^{13}$

\section{Osteoarticular diseases}

\section{Osteopenia and osteoporosis}

Identification of osteopenia and osteoporosis was verified by Dual Energy X-ray Absorptiometry (DXA), in a Lunar DPX-MD model (software 4.7). Bone mineral density of the total proximal femur was analyzed according manufacturer protocol, by an experienced technician. Subjects were classified as having osteopenia or osteoporosis according to the criteria established by the World Health Organization ${ }^{14}$.

\section{Other diseases}

The presence of arthritis, osteoarthritis, herniated disc, back pain and scoliosis was obtained using a summarized self-reported questionnaire of morbidities from the Standard Health Questionnaire for Washington State ${ }^{15}$. Questions were closed, and analyzed the presence/absence of chronic diseases, divided into three groups: metabolic, cardiovascular and osteoarticular. 


\section{Physical performance}

Physical performance was analyzed by means of the tests of static balance, usual gait speed and lower limb strength, from the short battery of motor tests proposed by Guralnik et al. ${ }^{16}$.

For tests of standing balance, participants attempted to maintain the side-by-side, semi-tandem and tandem positions for 10 seconds. Participants were scored as: 0 , if they were unable to hold a side-by-side stand position for $10 \mathrm{sec}$ onds; 1 , if they could hold a side-by-side stand position for 10 seconds but were unable to hold a semi-tandem stand position for 10 seconds; 2, if they held a semi-tandem stand position for 10 seconds but were unable to hold a full tandem stand position for more than 2 seconds; 3 , if they held the full tandem stand position from 3 to 9 seconds; and 4, if they held the full tandem stand position for 10 seconds.

A usual pace, 3 meter walk, was timed from a standing start, and participants were scored according to the time, in $\mathrm{m} . \mathrm{s}^{-1}$. Time on the faster of two walks was recorded to define scores: 0 , if they were unable to hold a 3 meter walk; $1, \leq 0.43$ m.s s $^{-1} ; 2,0.44-0.60 \mathrm{~m} . \mathrm{s}^{-1} ; 3,0.61-0.77 \mathrm{~m} . \mathrm{s}^{-1}$; and 4 , $\geq 0.78 \mathrm{~m} . \mathrm{s}^{-1}$.

For lower limb strength, participants were asked to fold their arms across their chest and to stand up once from a chair. If successfully, they were asked to stand up and sit down five times as quickly as possible, finishing the fifth repetition on the stand position. Scores were as follows, according to time of execution: 0 , if they were unable to hold a repeat chair stands; $1,>16.7 \mathrm{sec}$ onds; 2, 16.6-13.7 seconds; 3, 13.6-11.2 seconds; and $4, \leq 11.1$ seconds.

A summary performance score, ranging from 0 to 12 , was created by the summation of the scores for the standing balance, gait speed, and rising from a chair 5 times tests. Older people who scored, for each test, from 0 to 2 points, or 0 to 6 points, for the overall score, were classified as low physical performance.

All assessments were performed by trained professionals from the CELAPAM (Center of Studies of the Laboratory of Assessment and Prescription of Motor Activity), of the Universidade Estadual Paulista, Campus of Presidente Prudente.

\section{Statistical Analysis}

Normality of the data set was analyzed by Komolgorov-Smirnov test. Descriptive statistics of continuous variables consisted of mean and stan- dard deviation. The chi-square test was used to analyze the proportion of osteoarticular diseases according to gender. Participants were divided into two groups of osteoarticular diseases (presence and absence) and Students' t test for independent samples were used for the comparison of variables between both groups. Multivariate logistic regression was performed to analyze the association between each group of osteoarticular disease (independent variables) and low physical performance (dependent variable) with adjustment for sex, and linear regression was used to analyze the correlation between the scores in each physical performance test and overall score with total number of osteoarticular diseases. The SPSS software, version 17.0 was used and the significance level was set at $5 \%$.

\section{Results}

The values shown in Table 1 refer to the mean and standard deviation of the continuous variables and comparison according to groups. Age and height did not presented significant differences between groups. Those without OD presented higher values for weight $(p=0.032)$, BMI $(\mathrm{p}=0.026)$ and BMD $(\mathrm{p}=0.000)$ compared to those with OD.

The proportion of each type of OD according to gender is presented in Figure 1. Men presented higher proportion of osteopenia/osteoporosis compared to women $(\mathrm{p}=0.013)$. The proportion of older people with arthritis/osteoarthritis for women and men was $33 \%$ and $26 \%$, respectively $(\mathrm{p}=0.464)$. The proportion of women and men with OD in the spine was $19 \%$ and $12 \%$, respectively $(p=0.336)$. Considering all OD, no statistical differences $(p=0.423)$ were observed in the proportion between men (32\% with OD) and women (53\% with OD).

Comparisons between physical performance of subjects with and without OD (total sample and according to gender) are presented in the Table 2 . The results indicate that there were no differences for physical performance, measured by each test, and overall score, between both groups $(\mathrm{p}<0.05)$. According to gender, male with OD presented lower performance in gait speed, balance and overall score $(\mathrm{p}<0.05)$, whereas for the female group, no significant differences were observed for those with and without OD.

The association between OD and low physical performance (according to overall score) is presented in Table 3. Despite osteopenia/osteo- 
Table 1. Differences in main characteristics between osteoarticular diseases groups (absence $v s$ presence of OD).

\begin{tabular}{lcccc}
\hline \multicolumn{1}{c}{ Variables } & $\begin{array}{c}\text { Absence of OD } \\
(\mathbf{n}=\mathbf{3 0}) \\
\text { Mean } \pm \text { SD }\end{array}$ & $\begin{array}{c}\text { Presence of OD } \\
(\mathbf{n}=\mathbf{1 0 5}) \\
\text { Mean } \pm \text { SD }\end{array}$ & $\mathbf{t}$ & $\mathbf{p}$ \\
\hline Age (years) & $82.4 \pm 3.5$ & $83.5 \pm 2.8$ & -1.615 & 0.109 \\
Weight $(\mathrm{Kg})$ & $72.8 \pm 20.1$ & $62.4 \pm 13.2$ & 2.284 & 0.032 \\
Stature $(\mathrm{cm})$ & $155.8 \pm 16.1$ & $155.6 \pm 9.6$ & 0.047 & 0.963 \\
BMI $\left(\mathrm{kg} / \mathrm{m}^{2}\right)$ & $30.4 \pm 9$ & $25.6 \pm 4.1$ & 2.384 & 0.026 \\
BMD femur $\left(\mathrm{g} / \mathrm{cm}^{2}\right)$ & $0.95 \pm 0.18$ & $0.78 \pm 0.15$ & 4.114 & 0.000 \\
\hline
\end{tabular}

$\mathrm{t}=\mathrm{t}$ value for the Student $\mathrm{t}$ test for independent samples; $\mathrm{p}=$ significance level; $\mathrm{SD}=$ standard deviation; $\mathrm{BMD}=$ bone mineral density.

Table 2. Physical performance of Brazilian over 80 years with and without osteoarticular diseases, total and according to gender.

\begin{tabular}{|c|c|c|c|}
\hline Tests & $\begin{array}{c}\text { Absence of OD } \\
\mathbf{n}=30 \\
\text { Mean } \pm \text { SD }\end{array}$ & $\begin{array}{c}\text { Presence of OD } \\
\mathbf{n}=105 \\
\text { Mean } \pm \text { SD }\end{array}$ & $\mathrm{p}$ \\
\hline Speed (points) & $2.1 \pm 1.2$ & $1.8 \pm 1.1$ & 0.250 \\
\hline Balance (points) & $2.9 \pm 1.4$ & $2.6 \pm 1.4$ & 0.462 \\
\hline LL strength (points) & $1.6 \pm 1.2$ & $1.6 \pm 1.3$ & 0.889 \\
\hline All tests (points) & $6.5 \pm 3.1$ & $6.0 \pm 3.3$ & 0.428 \\
\hline \multirow[b]{2}{*}{ Tests } & \multicolumn{2}{|c|}{ Male } & \multirow[b]{2}{*}{$\mathbf{p}$} \\
\hline & $\begin{array}{c}\text { Absence } \\
\mathbf{n}=7 \\
\text { Mean } \pm \text { SD }\end{array}$ & $\begin{array}{c}\text { Presence } \\
n=42 \\
\text { Mean } \pm \text { SD }\end{array}$ & \\
\hline Speed (points) & $2.9 \pm 0.7$ & $1.7 \pm 1.1$ & 0.013 \\
\hline Balance (points) & $3.7 \pm 0.4$ & $2.6 \pm 1.5$ & 0.000 \\
\hline LL strength (points) & $2.3 \pm 0.9$ & $1.4 \pm 1.3$ & 0.114 \\
\hline \multirow[t]{2}{*}{ All tests (points) } & $8.8 \pm 1.0$ & $5.9 \pm 3.3$ & 0.000 \\
\hline & \multicolumn{2}{|c|}{ Female } & \\
\hline Tests & $\begin{array}{c}\text { Absence } \\
\mathbf{n}=23 \\
\text { Mean } \pm \text { SD }\end{array}$ & $\begin{array}{c}\text { Presence } \\
n=63 \\
\text { Mean } \pm \text { SD }\end{array}$ & $\mathbf{p}$ \\
\hline Speed (points) & $1.8 \pm 1.3$ & $1.9 \pm 1.1$ & 0.913 \\
\hline Balance (points) & $2.6 \pm 1.5$ & $2.6 \pm 1.4$ & 0.808 \\
\hline LL strength (points) & $1.4 \pm 1.2$ & $1.6 \pm 1.3$ & 0.418 \\
\hline All tests (points) & $5.8 \pm 3.2$ & $6.2 \pm 3.2$ & 0.634 \\
\hline
\end{tabular}

$\mathrm{p}=$ Student $\mathrm{t}$ test for independent samples significance level; $\mathrm{LL}=$ lower limbs, SD = standard deviation.

porosis, where it was verified in older people with such diseases chances $173 \%$ higher to present low physical performance, other OD was not associated to low physical performance ( $\mathrm{p}>0.05)$.

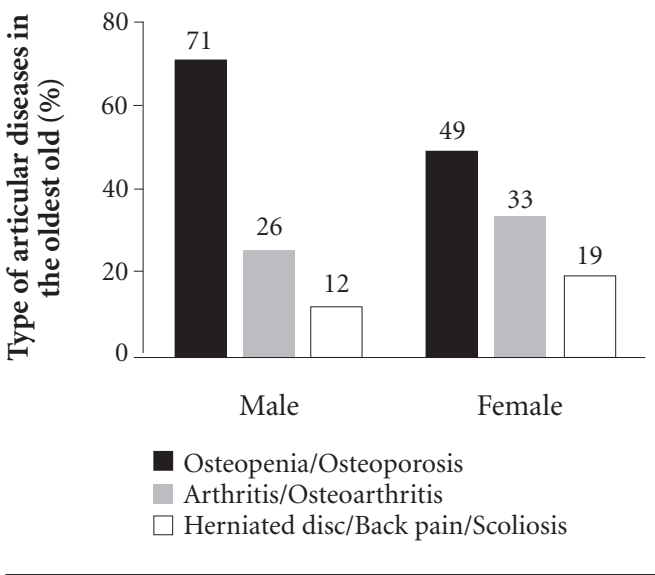

Figure 1. Prevalence of each type of osteoarticular disease according to gender.

When continuous variables (score in each test and total score with total number of OD) were analyzed by the linear regression test, adjusted for sex, no correlations were observed for any of that $(p>0.05)$. For the analysis between score for gait speed and total number of OD, a marginal significance was verified $(p=0.051)$, where for each osteoarticular disease added, a reduction in gait speed in 0.2569 m.s-1 was observed.

\section{Discussion}

This cross-sectional study aimed to compare physical performance scores of the older individuals (over 80 years-old) with and without OD. The main findings were that men with OD presented higher impaired physical performance compared those without OD, and men and women with osteopenia and osteoporosis were at higher risk of low physical performance, compared to those without these diseases.

The OD are highly prevalent in older peo$\mathrm{ple}^{5,17}$ and between all kinds of OD, arthritis, osteoarthritis and osteoporosis/osteopenia are the most prevalent $t^{18,19}$. When analyzed the proportion of all OD, it was verified that $47 \%$ of the women and $31 \%$ of the men presented one or more OD. Our findings corroborate with most studies in the literature, which states that aging increases the incidence of $\mathrm{OD}^{2}$, decreasing, in consequence, physical performance of individuals affected by these diseases ${ }^{9,20,21}$. 
Table 3. Association between osteoarticular diseases and low physical performance of older people over 80 years.

\begin{tabular}{lccc}
\hline \multicolumn{1}{c}{ Diseases } & \multicolumn{3}{c}{ Low physical performance } \\
\cline { 2 - 4 } & $\mathbf{n}(\%)$ & OR (CI95\%) & $\mathbf{p}$ \\
\hline Osteopenia/osteoporosis & $22(31.9)$ & 1.00 & 0.007 \\
$\quad$ No & $47(68.1)$ & $2.73(1.31-5.66)$ & \\
$\quad$ Yes & & & 0.897 \\
Arthritis/osteoarthritis & $49(70.0)$ & 1.00 & 0.482 \\
$\quad$ No & $21(30.0)$ & $0.95(0.46-1.99)$ & \\
Yes & & 1.00 & \\
Herniated disc/back pain/scoliosis & $57(81.4)$ & $1.39(0.55-3.54)$ & \\
$\quad$ No & $13(18.6)$ & & \\
Yes & & & \\
\hline
\end{tabular}

${ }^{+} \mathrm{OR}=$ adjusted for sex.

Concerning osteoporosis, the prevalence is higher in women, however, it is increasing considerably in men, especially in the older group ${ }^{22}$. In Brazilian population, Tanaka et al. ${ }^{23}$ identified prevalence of $44.6 \%$ of osteopenia and $15.4 \%$ of osteoporosis in men aged over 50 years, and this prevalence increased significantly with age, reaching $75 \%$ of in subjects older than 80 years. Our findings, with $71 \%$ of men with osteopenia/ osteoporosis, corroborate with the study aforementioned. The presence of osteoporosis is responsible for low physical performance in adults and older people $e^{20,24}$. Few studies have investigated this aspect in men, mainly aged over 80 years. This is alarming, since one study showed that one in each four men aged over 60 years will have a fracture due to osteoporosis ${ }^{25}$. In our study we found a high proportion of men with osteopenia/osteoporosis and this evidence explain the factor they presented higher limitation of physical performance when a comparison was performed between physical performance of subjects with and without any kind of OD, according to gender. One explanation for the increased occurrence of osteoporosis in the oldest men is due to the accentuated bone loss related to the low levels of testosterone. Unlike the women, when the decreasing of estrogen initiates at the age of 50 years, approximately, testosterone in men persists in functional levels until the seventh decade of life, becoming more susceptible to diseases ${ }^{26}$.

Regarding the presence of arthritis/ osteoarthritis in the older people, the prevalence is higher in women than in men ${ }^{18,27}$. In our study, even without statistical significance, higher prevalence of arthritis/osteoarthritis was observed in women. When arthritis is analyzed among the OD,
Winter et al. ${ }^{21}$ observed that individuals with this disease presented limited physical performance compared to their healthy peers. Van Dijk et al. ${ }^{8}$ observed in subjects with osteoarthritis worsening of limitations in activities in a period of three years. Liposcki and Rosa Neto ${ }^{7}$ used the Motor Scale for Older people to assess balance and found that $71 \%$ of the older people with osteoarthritis were classified as lower balance group, and, in addition, $\sim 30 \%$ of them reported falls in the last six months. Some prognostic factors for worsening of limitation physical performance include increased pain, reduced muscle mass and strength, and physical inactivity ${ }^{8,28}$.

Finally, a high prevalence of spine diseases in older people people of both gender ${ }^{3,4,19}$ was also observed in our study. Spine diseases can reduce the physical performance of older people due to the local pain and pain-related fear caused by these diseases ${ }^{29,30}$. The pain-related fear can cause avoidance behaviours related to specific movements, that are believed to be potentially painful or at risk of reinjury ${ }^{31}$. Also, low back pain is associated with difficulties in performing activities of daily living and risk of falls ${ }^{32}$. Kose and Hatipoglu ${ }^{33}$ observed that subjects with low back pain caused by lumbar disc herniation experienced physical disabilities due to the pain. Their daily living activities were affected by these disabilities and the intensity of pain affects the level of disability. Similar results were found by Champagne et al. ${ }^{9}$, where older people women with chronic low back pain presented lower physical performance score compared to controls.

Our study was performed to compare physical performance of the men and women over 80 years-old with and without theses OD, and was 
also revealed that older men with OD presented lower physical performance compared to those without diseases. Some studies have shown gender differences regarding physical performance, with a greater chance of declining physical performance for women ${ }^{34,35}$ in all age groups in adults and older people ${ }^{36}$. One explanation for this fact can be attributed to a higher incidence of OD in women ${ }^{34,37}$. However, in our study, men also showed a high prevalence of osteoarticular diseases, with differences statistically significant regarding the presence of osteopenia/osteoporosis. This evidence may explain the fact that men have shown more limited physical performance compared to women.

Despite the relevance of the results found in this study, some limitations should be highlighted: i) the lack of more physical tests, such as flexibility and coordination tests, applied in the analysis of physical performance, ii) the use of self-reported diseases questionaries (arthritis, osteoarthritis, herniated disc, back pain and scoliosis), which may underestimated or overestimated prevalence rates and, iii) the prevalence osteoporotic fractures is not available, since this factor may manage the effect of osteoporosis on physical performance. However it is noteworthy that there are still few studies that aimed to verify such aspects in the older people over the age of 80 years.

In summary, we concluded that at the age of 80 years or more, a high prevalence of OD was verified, especially in men, and the presence of these diseases interfered negatively the physical performance.

\section{Collaborations}

Study conception and design: VR Santos, IC Gomes, IF Freitas Júnior. Acquisition of data: VR Santos, IC Gomes, IF Freitas Júnior. Analysis and interpretation of data: VR Santos, LA Gobbo, DGD Christofaro. Drafting of manuscript: VR Santos, LA Gobbo. Critical revision: VR Santos, LA Gobbo, J Mota, S Gobbi, IF Freitas Júnior.

\section{Acknowledgments}

This work was supported by a scholarship (VRS) from the Conselho Nacional de Desenvolvimento Científico e Tecnológico (CNPq), Brazil. 


\section{References}

1. Minayo MCS. Aging of the Brazilian population and challenges for the health sector. Rep Public Health 2012; 28(2):208-209.

2. Kalichman L, Korostishevsky M, Batsevich V, Kobyliansky E. Hand osteoarthritis in longevity populations. Aging Clin Exp Res 2011; 23(5-6):457-462.

3. Urrutia J, Diaz-Ledezma C, Espinosa J, Berven SH Lumbar scoliosis in postmenopausal women: prevalence and relationship with bone density, age, and body mass index. Spine 2011; 36(9):737-740.

4. Kebaish KM, Neubauer PR, Voros GD, Khoshnevisan MA, Skolasky RL. Scoliosis in adults aged forty years and older: prevalence and relationship to age, race, and gender. Spine 2011; 36(9):731-736.

5. Sebastião E, Christofoletti G, Gobbi S, Hamanaka AYY Physical activity and chronic diseases in older people from Rio Claro-SP. Motriz 2008; 14(4):381-388.

6. Pilger C, Menon M H, Mathias TAF. Socio-demographic and health characteristics of elderly individuals: support for health services. Rev Latino-Am Enfermagem 2011; 19(5):1230-1238.

7. Liposcki DB, Rosa Neto F. Prevalence of osteoarthritis, falls and relationship with the balance the elderly. Ter Man 2008; 6(26):235-238.

8. Van Dijk GM, Veenhof C, Spreeuwenberg P, Coene N, Burger BJ, Van Schaardenburg D, Van den Ende CH, Lankhorst GJ, Dekker J; CARPA Study Group. Prognosis of limitations in activities in osteoarthritis of the hip or knee: a 3-year cohort study. Arch Phys Med Rehabil 2010; 91(1):58-66.

9. Champagne A, Prince F, Bouffard V, Lafond D. Balance, falls-related self-efficacy, and psychological factors amongst older women with chronic low back pain: A preliminary case-control study. Rehabil Res Pract 2012; 2012:430374.

10. Fiedler MM, Peres KG. Functional status and associated factors among the elderly in a southern Brazilian city: a population-based study. Rep Public Health 2008; 24(2):409-415.

11. Cardoso JH, Costa JSD. Epidemiological characteristics, functional capacity and factors associated with elders in a private health insurance. Cien Saude Colet 2010; 15(6):2871-2878.

12. Instituto Brasileiro de Geografia e Estatística (IBGE). Censo Demográfico e Contagem da População: População residente por gênero, situação e grupos de idade. Rio de Janeiro: IBGE; 2010.

13. Freitas Junior I, Bueno DR, Buonani C, Codogno JS, Conterato I, Fernandes RA, Fragoso Neto RA, Messias K, Rosa CSC. Padronização de Técnicas Antropométricas. Presidente Prudente: Cultura Acadêmica; 2009.

14. World Health Organization (WHO). Prevention and management of osteoporosis. Geneva: WHO; 2003. Report of a WHO scientific group

15. Washington State Health Insurance Pool (WSHIP). Standard Health Questionnaire for Washington State. Washington: WSHIP; 2005.

16. Guralnik JM, Simonsick EM, Ferrucci L, Glynn RJ, Berkman LF, Blazer DG, Scherr PA, Wallace RB. A short physical performance battery assessing lower extremity function: association with self-reported disability and prediction of mortality and nursing home admission. $J$ Gerontol 1994; 49(2):M85-M94.
17. Rodrigues RAP, Scudeller PG, Pedrazzi EC, Schiavetto FV, Lange C. Morbility and interference in seniors' functional ability. Acta Paul Enferm 2008; 21(4):643648.

18. Pedrazzi EC, Rodrigues RA, Schiaveto FV. Referred morbidity and functional capacity of the elderly. Ciênc Cuid Saúde 2007; 6(4):407-413.

19. Santos KA, Koszuoski R, Dias-da-Costa JS, Pattussi MP. Factors associated with functional incapacity among the elderly in Guatambu, Santa Catarina State, Brazil. Rep Public Health 2007; 23(11):2781-2788.

20. Hübscher M, Vogt L, Schmidt K, Fink M, Banzer W. Perceived pain, fear of falling and physical function in women with osteoporosis. Gait Posture 2010; 32(3):383-385.

21. Winter CC, Brandes M, Muller C, Schubert T, Ringling M, Hillmann A, Rosenbaum D, Schulte TL. Walking ability during daily life in patients with osteoarthritis of the knee or the hip and lumbar spinal stenosis: a cross sectional study. BMC Musculoskeletal Disorders 2010; 11:233.

22. Ducharme N. Male Osteoporosis. Clin Geriatric Med 2010; 26(2):301-309.

23. Tanaka T, Latorre MR, Jaime PC, Florindo AA, Pippa MG, Zerbini CA. Risk factors for proximal femur osteoporosis in men aged 50 years or older. Osteoporos Int 2001; 12(11):942-949.

24. Waters DL, Hale L, Grant AM, Herbison P, Goulding A. Osteoporosis and gait and balance disturbances in older sarcopenic obese New Zealanders. Osteoporos Int 2010; 21(2):351-357.

25. Gruntmanis U. Male osteoporosis: deadly, but ignored. Am J Med Sci 2007; 333(2):85-92.

26. Oliveira LGO, Guimarães MLR. Male osteoporosis. Rev Bras Ortop 2010; 45(5):392-396.

27. Zuart-Alvarado R. Osteoarthrosis and associated chronic pathologies in patients of a primary care unit. Rev Med Inst Mex Seguro Soc 2011; 49(6):637-642.

28. Pisters MF, Veenhof C, Van Dijk GM, Heymans MW, Twisk JW, Dekker J. The course of limitations in activities over 5 years in patients with knee and hip osteoarthritis with moderate functional limitations: risk factors for future functional decline. Osteoarthritis Cartilage 2012; 20(6):503-510.

29. Vincent HK, Seay AN, Montero C, Conrad BP, Hurley RW, Vincent KR. Functional pain severity and mobility in overweight older men and women with chronic low-back pain-part I. Am J Phys Med Rehabil 2013; 92(5):430-438.

30. Dellaroza MS, Pimenta CA, Duarte YA, Lebrão ML. Chronic pain among elderly residents in Sao Paulo, Brazil: prevalence, characteristics, and association with functional capacity and mobility (SABE Study). Rep Public Health 2013; 29(2):325-334.

31. Leeuw M, Goossens ME, Linton SJ, Crombez G, Boersma K, Vlaeyen JW. The fear-avoidance model of musculoskeletal pain: current state of scientific evidence. $J$ Behav Med 2007; 30(1):77-94.

32. Hicks GE, Gaines JM, Shardell M, Simonsick EM Associations of back and leg pain with health status and functional capacity of older adults: findings from the retirement community back pain study. Arthritis Rheum 2008; 59(9):1306-1313. 
33. Kose G, Hatipoglu S. The effect of low back pain on the daily activities of patients with lumbar disc herniation: a Turkish military hospital experience. J Neurosci Nurs 2012; 44(2):98-104.

37. Alexandre TS, Corona LP, Nunes DP, Santos JL, Duarte YA, Lebrão ML. Gender differences in incidence and determinants of disability in activities of daily living among elderly individuals: SABE study. Arch Gerontol Geriatr 2012; 55(2):431-437.

35. Weiss CO, Wolff JL, Egleston B, Seplaki CL, Fried LP. Incident preclinical mobility disability (PCMD) increases future risk of new difficulty walking and reduction in walking activity. Arch Gerontol Geriatr 2012; 54(3):e329-333.

36. Miszkurka M, Zunzuneguia MV, Langloisa EV, Freemanb EE, Kouandac S, Haddada S. Gender differences in mobility disability during young, middle and older age in West African adults. Glob Public Health 2012; 7(5):495-508.

37. Whitson HE, Landerman LR, Newman AB, Fried LP, Pieper CF, Cohen HJ. Chronic medical conditions and the gender-based disparity in disability: the cardiovascular health study. J Gerontol A Biol Sci Med Sci 2010; 65(12):1325-1331.

Artigo apresentado em 22/04/2015

Aprovado em 28/08/2015

Versão final apresentada em 30/08/2015 